\title{
Changes in the foraging dive behaviour and energetics of king penguins through summer and autumn: a month by month analysis
}

\author{
L. G. Halsey ${ }^{1,2, *}$, P. J. Butler ${ }^{2}$, A. Fahlman ${ }^{3}$, C. A. Bost ${ }^{4}$, Y. Handrich ${ }^{5}$ \\ ${ }^{1}$ School of Human and Life Sciences, Roehampton University, London SW15 4JD, UK \\ ${ }^{2}$ School of Biosciences, The University of Birmingham, Edgbaston, Birmingham B15 2TT, UK \\ ${ }^{3}$ North Pacific Universities Marine Mammal Research Consortium, University of British Columbia Marine Mammal Research \\ Unit, 2202 Main Hall, Vancouver, British Columbia, Canada V6T 1Z4 \\ ${ }^{4}$ Centre d'Etude Biologiques de Chizé-Centre National de la Recherche Scientifique, Villiers en Bois, 79360 Beauvoir Sur \\ Niort Cedex, France \\ ${ }^{5}$ Institut Pluridisciplinaire Hubert Curien (IPHC), UMR 7178 CNRS-ULP, Département Ecologie, Physiologie et Ethologie \\ (DEPE), 23 rue Becquerel, 67087 Strasbourg Cedex 02, France
}

\begin{abstract}
King penguins Aptenodytes patagonicus are known to change their diving behaviour in response to changes in both prey location and their breeding status through the early stages of the breeding cycle (austral summer and autumn). However, little information exists on whether and how these changes affect the energy expenditure of such behaviour. By deploying heart rate and hydrostatic pressure data loggers, we investigated detailed changes in the dive time budgeting of king penguins during foraging dives across the breeding season, in the same individuals, and the associated changes in estimated oxygen consumption during those dives. Maximum dive depth, duration, bottom duration, feeding events (indicated by wiggles) per dive and post-dive duration increased through the study period. While a foraging dive later in the breeding season was energetically more costly than a dive earlier in the season, the overall rate of energy expenditure did not change, nor did energy cost per unit prey capture. These findings indicate an ability of king penguins to adjust their foraging dive behaviours through the summer and autumn without affecting the energetic costs of diving to capture prey. Such plasticity may be necessary to compensate for changes both in prey location and abundance, and in the energy requirements of the chick over time.
\end{abstract}

KEY WORDS: Behavioural plasticity · Diving $\cdot$ Energy costs $\cdot$ Heart rate $\cdot$ Aptenodytes patagonicus $\cdot$ Seabirds Resale or republication not permitted without written consent of the publisher

\section{INTRODUCTION}

Penguins show plasticity in their foraging behaviour, changing their diving patterns in response to variations in prey availability, prey type and energy requirements over time (e.g. Hull 2000, Rodary et al. 2000, Kato et al. 2003, Tremblay \& Cherel 2003, Green et al. 2005b). King penguins Aptenodytes patagonicus are known to change their diving behaviour in response to changes in prey location. During the austral summer, king penguins that inhabit the southern
Indian Ocean forage around the polar frontal zone at relatively deep depths, but go farther south to Antarctic waters in winter, where they are able to find prey by diving to shallower depths (Charrassin \& Bost 2001).

King penguins are also known to change their diving behaviour to best suit their stage of the breeding cycle. Although the start of the breeding cycle varies, it occurs for the majority of king penguins around the beginning of the summer in December. While foraging at this time, the birds need only obtain food for themselves. However, once the chick has hatched, from 
about late January onwards, the foraging parent must obtain sufficient food not only to sustain itself while brooding the chick (and hence fasting) but also to feed to the chick (Gauthier-Clerc et al. 2000). When foraging, during both the incubating stage and at the chickrearing stage, the parents travel to the polar frontal zone to feed in summer (Charrassin \& Bost 2001), but chick-rearing birds dive deeper than incubating birds (Charrassin et al. 1998). The suggested reason for this is that deeper dives are undertaken to reach denser patches of myctophid fish (Zasel'sliy et al. 1985, Charrassin et al. 1998), the most common prey of king penguins (Cherel \& Ridoux 1992, Pütz \& Bost 1994), so that a greater amount of food energy is obtained per dive (Charrassin et al. 1998). While such dives may use more energy (Tremblay \& Cherel 2003, Halsey et al. 2006a), it is assumed that net energy gain is higher, which is necessary to meet overall energetic requirements during brooding.

During foraging trips towards the end of summer and the beginning of autumn (March), king penguins tend to undertake foraging dives at a particularly high frequency (Charrassin et al. 1999). At this stage of breeding, the now thermally emancipated chick needs to grow rapidly and build fat stores in preparation for the ensuing winter fast (Stonehouse 1960, Weimerskirch et al. 1992). The chick requires large quantities of food at a high rate (Cherel \& Ridoux 1992, van Heezik et al. 1993, Cherel et al. 1996) to fuel high energy requirements (Halsey et al. 2008) while it is still dependent on its parents. To accomplish this, at this stage of the breeding cycle, the parents spend shorter periods of time with the chicks (Weimerskirch et al. 1992), and coupled with a high frequency of foraging dives to dense prey patches (Charrassin et al. 1999), the parents can increase food provision to the chick. By mid autumn, the majority of surviving chicks are creching and this is when both parents can forage independently to feed the chick (i.e. without the limitation of ensuring that one parent is always with the chick, Charrassin et al. 1999), thus lessening the demands on themselves. Furthermore, the energy demands of the chicks are reduced (Halsey et al. 2008). However, by this time, myctophid fish have migrated to greater depths (Lancraft et al. 1991, Kozlov et al. 1993), which presumably makes them more difficult to capture. This reduces the foraging success of seabirds (Le Maho et al. 1993), including king penguins, which continue to undertake foraging dives at a high frequency (Charrassin et al. 1999).

Summer and autumn are clearly periods of changing foraging challenges and energetic demands on breeding king penguins. The present study used implanted depth-heart rate data loggers to investigate both detailed changes in the behaviour of king penguins at- tempting to raise a chick, characterising changes specifically occurring in the patterns of foraging dives across the incubating and chick-rearing periods, as well as the associated changes in energy costs of those dives. A number of studies have investigated variations in the behaviour of king penguins at different times of the year and during different stages of the breeding cycle (Charrassin et al. 1998, 1999, 2002, Moore et al. 1999, Charrassin \& Bost 2001), but only one study has looked at how differing diving behaviour affects energy expenditure during foraging (Halsey et al. $2007 \mathrm{~b}$ ). However, the latter study did not consider time of year. Indeed, macaroni penguins Eudyptes chrysolophus are the only seabird species for which changes in diving behaviour and energetics have been studied continuously over consecutive months (Green et al. 2005a,b, 2009).

\section{MATERIALS AND METHODS}

Study birds and logger deployment. The study was undertaken at the French research station on Possession Island $\left(46^{\circ} 25^{\prime} \mathrm{S}, 51^{\circ} 45^{\prime} \mathrm{E}\right)$, Crozet Archipelago, during 3 field seasons over consecutive austral summers (2002-03, 2003-04, 2004-05). King penguins used in the study were male birds at the colony of La Baie du Marin. A total of 32 penguins incubating eggs was captured between November 2002 to January 2003 and between December 2003 to March 2004 (mean mass \pm $\mathrm{SE}=14.3 \pm 0.1 \mathrm{~kg}$ ). A custom-built depth and heart rate (fH) data logger (Woakes et al. 1995) was implanted into the abdominal cavity of each bird (surgical procedures are detailed in Froget et al. 2004 and Fahlman et al. 2005). The data loggers $(30 \times 25 \times$ $15 \mathrm{~mm}, 30 \mathrm{~g}[<1 \%$ of the mean body mass of a king penguin]) had 16 to $64 \mathrm{MB}$ of memory and recorded $\mathrm{fH}$ and water depth (to an accuracy of $1 \mathrm{~m}$ ) every second. Immediately after surgery, all birds and their eggs were returned to the exact site from where they had been captured. The implantation was performed at least $2 \mathrm{~d}$ after the egg exchange, so that each bird was settled on its egg and continued to incubate after the disturbance of handling and surgery. Between 15 and 20 d later, the nesting parent bird exchanged places with its returning mate and undertook a foraging trip at sea. The loggers were implanted in each bird in one of 2 years of data collection, and furthermore there was variation in the time of year when they were implanted (Table 1). There were also considerable differences in the duration that the loggers recorded field data (1 to $10 \mathrm{mo}$ ).

A tag typically used for marking fish was attached to the back of each bird and a picric acid mark applied to its front. These aided in identifying the birds for recap- 
Table 1. Aptenodytes patagonicus. Data used in the present study recorded on implanted loggers. na: not applicable

\begin{tabular}{|lcccc|}
\hline Field season & Bird code & Implantation date & Egg-laying date & $\begin{array}{c}\text { Months during which at-sea data } \\
\text { are available relevant to the } \\
\text { present study }\end{array}$ \\
\hline $2002-03$ & $1,2,5,6,7$ & 24 Nov-3 Dec & $22-29$ Nov & Dec \\
$2002-03$ & $3,5,8$ & 28 Dec, 31 Dec, 11 Jan & 25 Dec, 29 Dec, 10 Dec & Jan, Feb, Mar, Apr \\
$2002-03$ & 10,11 & 21 Jan, 22 Jan & 20 Jan, 21 Jan & Jan, Feb, Mar \\
$2003-04$ & 16 & 21 Dec & 15 Dec & Jan, Feb, Mar, Apr \\
$2003-04$ & 17 & 22 Dec & Jan, Feb, Mar, Apr \\
$2003-04$ & $24^{\text {a }}$ & 2 Mar & Mar, Apr \\
and & \\
\hline
\end{tabular}

ture and removal of the logger, which was undertaken either in the same season of deployment or the following season. The procedures for the removal of the loggers were similar to those for implantation. Over the 3 field seasons, a total of 20 loggers were retrieved. Of these, heart rate data had been recorded and could be extracted from 12 loggers (Table 1).

Data analysis. After retrieval of a logger, data were extracted, prepared and initially analysed using purpose-written computer programs in Matlab (v. 6.0, The MathsWorks). Data from December to April, inclusive, were statistically analysed. Mean values for all behavioural variables included in analyses and for heart rate were calculated for each bird and month. These data were tested for normality in GraphPad Prism (v. 3.0, GraphPad Software) using Kolmogorov-Smirnov tests. Further analyses of these data involved single and multiple linear regressions (fitted using the restricted maximum likelihood [REML] method) and were performed in the statistical package JMP (v. 7.0.2, SAS Institute). Data for all birds were present in each analysis and an individual was always included as a random factor. This variable accounted for differences between birds, which could be the result of differences in the foraging environment between the 2 years of data recording and/or differences in stage of the breeding cycle at any given time of the year, as well as physiological/morphological differences. Thus, despite the analyses involving pooled data for earlier and later breeding birds, and for 2 different years, the results provided valuable information on changes in diving behaviour and associated energetic costs in king penguins due to the progression of the year through summer and autumn.

Dive analysis. The analysis of data in the present study was based upon the foraging dives recorded for each penguin. Foraging dives were defined as dives with maximum depths greater than $50 \mathrm{~m}$ (Halsey et al. 2007a). For each dive, the following features were extracted: dive duration (seconds), the post dive period (seconds), bottom duration (seconds), maximum depth (metres). We also determined the number of wiggles during the dive (which are significantly related to the number of ingestions recorded per dive and in king penguins occur mainly during the bottom phase; Bost et al. 2007) and the raggedness of the bottom phase of the dive (degree of raggedness in $\mathrm{m} \mathrm{s}^{-1}$, see Fig. 1). It was assumed that the relationship between number of wiggles and number of successful prey captures does not vary with time of year. The bottom phase of dives, the wiggles within dives and the degree of raggedness were identified using the criteria detailed in Halsey et al. (2007a). Briefly, the bottom phase was identified as being from the first wiggle in the deepest $25 \%$ of the dive to the last wiggle within this same depth range. The degree of raggedness is calculated as the sum of the ranges in depth of the wiggles during the bottom phase divided by the duration of the bottom phase. A high degree of raggedness indicates a high rate of wiggles during the bottom phase of a dive and/or large changes in depth associated with those wiggles (Fig. 1). This variable may be a valu-

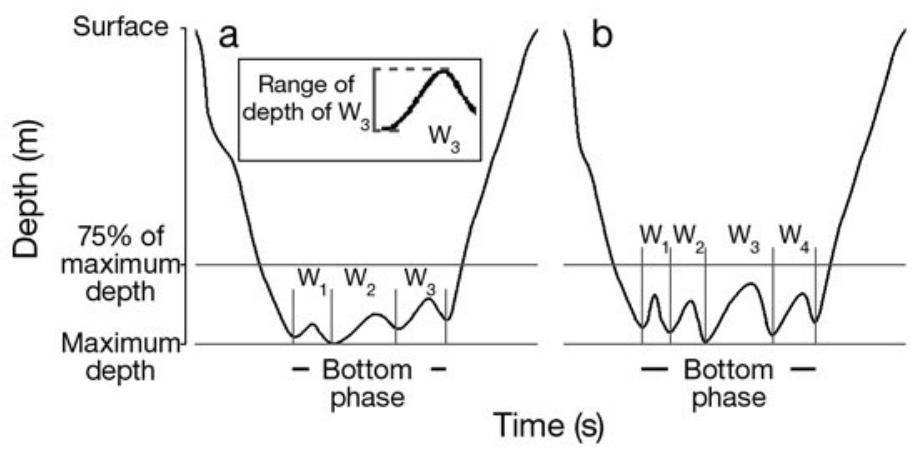

Fig. 1. Aptenodytes patagonicus. Schematic of 2 foraging dives with the same maximum depth, to illustrate the definition of the bottom phase of the dive and the degree of raggedness $\left(\mathrm{m} \mathrm{s}^{-1}\right)$ of the bottom phase. Dive ' $b$ ' has a higher degree of raggedness than dive ' $a$ ' because, while both dives have a similar bottom phase duration, the bottom phase of dive ' $b$ ' includes more wiggles $\left(\mathrm{W}_{1-4}\right)$ and those wiggles have a greater range of depth (see Halsey et al. 2007a for more details). Wiggle 3 of dive ' $a$ ' is shown enlarged as an insert to clarify how the range of depth of a wiggle is defined 
able metric when considering the distribution of prey, or visibility of prey, in the water column.

A variable 'wiggle rate during the bottom period' (wiggles $\mathrm{min}^{-1}$ ) was derived from the number of wiggles during the bottom phase of the dive and bottom duration. The following ratios were derived from measured variables: bottom duration: dive duration and bottom duration: dive cycle duration. Mean $\mathrm{fH}$ in beats $\min ^{-1}\left(\mathrm{fH}_{\mathrm{dc}}\right)$ for each dive cycle (the dive and the subsequent surface period), total number of heart beats $\left(\Sigma \mathrm{H}_{\mathrm{dc}}\right)$ and the number of heart beats per wiggle as $\Sigma \mathrm{H}_{\mathrm{dc}}$ per wiggle, (i.e. the number of heart beats in a foraging dive cycle per prey capture event) were calculated.

The most suitable definition for the post dive period after a foraging dive in king penguins is unclear. Very shallow dives undertaken between foraging dives often represent subsurface travelling dives (Wilson 1995). However, some non-foraging dives by king penguins are up to $20 \mathrm{~m}$ or even $30 \mathrm{~m}$ deep and their main function may be to aid in recovery from foraging dives, perhaps to accelerate the metabolism of excess lactate (Kooyman et al. 1992, Ropert-Coudert et al. 2000, Butler 2004). Thus, in the present study, 2 definitions of the period after a foraging dive are considered. First, the surface period between a foraging dive and the next dive regardless of dive type $\left(d_{\text {sur }}\right)$ was calculated, which may represent the main period of reloading the oxygen stores after the previous dive. Second, the period between a foraging dive and the next foraging dive $\left(d_{\text {for }}\right)$ (Charrassin et al. 2002) was calculated. For both definitions, bout criterion interval analysis (Slater \& Lester 1982) was used to eliminate all dives with surface periods that represented pauses between bouts (Halsey et al. 2003). The bottom duration: dive cycle ratio, mean heart rate over the dive cycle $\left(\mathrm{fH}_{\mathrm{dc}}\right)$ and the total number of heart beats in a dive cycle $\left(\Sigma \mathrm{H}_{\mathrm{dc}}\right)$ were calculated based on both definitions of the post dive period (e.g. for $\mathrm{fH}_{\mathrm{dc}}$ : $\mathrm{fH}_{\mathrm{dc}}$ incorporating the surface duration until the next dive and $\mathrm{fH}_{\mathrm{dc}}$ incorporating the total post dive duration between foraging dives).

Mean values of each diving variable were calculated for each bird for each month. All the diving variables were normally distributed according to the Dallal \& Wilkinson (1986) approximation of Lilliefors' method. Single linear regressions and then multiple linear regressions were used to examine trends in the mean values. For each regression model, the dependent variable was a diving variable, month was included as a continuous independent variable representing time into the breeding season and individual bird was included as a random factor. Multiple regressions also included at least one diving variable as an independent variable. There was no evidence from the analysis software of a problem due to the multicollinearity of the variables. Acceptance of significance was set at $\mathrm{p}<$ 0.05 , and $0.05<\mathrm{p}<0.1$ was considered to represent a tendency. Plots of the residuals of the dependent variable against the predicted value of the dependent variable based on the linear regressions did not indicate heteroscedasticity in the data.

Bevan et al. (1992) showed that over complete dive cycles (dive plus the subsequent surface period), mean fH can be used to estimate rate of oxygen consumption $\left(\dot{V}_{\mathrm{O}_{2}}\right) \cdot \dot{V}_{\mathrm{O}_{2}}$ is an indirect measure of metabolic rate that can be converted to rate of energy expenditure, though this requires additional assumptions concerning the metabolic substrate being utilised (Walsberg \& Hoffman 2005). In the present study, estimates and associated SE values of mean total oxygen consumed over the dive cycle $\left(V_{\mathrm{O}_{2}}\right)$ were calculated from estimates and associated SEs of $\dot{V}_{\mathrm{O}_{2}}$ and measures and associated SEs of mean dive cycle duration. Estimated $\dot{V}_{\mathrm{O}_{2}}$ was calculated from mean $\mathrm{fH}_{\mathrm{dc}}$ calculated from multiple birds. This was achieved using conversion Eq. (1) derived in Fahlman et al. (2004), which is suitable for swimming king penguins (Halsey et al. 2007b). $\mathrm{SE}$ values of estimated $\dot{V}_{\mathrm{O}_{2}}\left(\mathrm{SE}_{\mathrm{E}}\right)$ were then calculated using the equation based on that derived by Green et al. (2001), which was further developed and detailed by Froget et al. (2004). Then, to obtain an estimate of $V_{\mathrm{O}_{2}}$, the estimate of $\dot{V}_{\mathrm{O}_{2}}$ was multiplied by the duration of the mean dive cycle. The $\mathrm{SE}_{\mathrm{E}}$ values associated with an estimate of $V_{\mathrm{O}_{2}}$ were calculated based on the method for combining non-additive variances, given no correlation between dive cycle duration and $\dot{V}_{\mathrm{O}_{2}}$ (Goodman, 1960):

$$
\mathrm{SE}_{\mathrm{E}}=d c^{2} \cdot \sigma_{-}^{2} \dot{V}_{\mathrm{O}_{2}}+\dot{V}_{\mathrm{O}_{2}} \cdot \sigma^{2} d c-\sigma^{2} d c \cdot \sigma^{2} \dot{V}_{\mathrm{O}_{2}}
$$

where $\sigma_{-}^{2} \dot{V}_{\mathrm{O}_{2}}$ is the variance of $\dot{V}_{\mathrm{O}_{2}}$ and $\sigma_{-}^{2} d c$ is the variance of the dive cycle duration which, adjusted to incorporate SEs, takes the following form:

$\frac{\sqrt{\left(d c^{2} \cdot\left(\sigma_{\mathrm{s}-} \dot{\mathrm{O}}_{\mathrm{O}_{2}} \cdot \sqrt{N}\right)^{2}\right)+\left(\dot{V}_{\mathrm{O}_{2}}^{2}\left(\sigma_{\mathrm{s}-} d c \cdot \sqrt{N}\right)^{2}\right)-\left(\left(\sigma_{s-} \dot{V}_{\mathrm{O}_{2}} \cdot \sqrt{N}^{2} \cdot\left(\sigma_{\mathrm{s}-} d c \cdot \sqrt{N}\right)^{2}\right)\right.}}{\sqrt{N}}$

where $d c$ is dive cycle duration, $\sigma_{\mathrm{s}-} \dot{V}_{\mathrm{O}_{2}}$ is the $\mathrm{SE}_{\mathrm{E}}$ of $\dot{V}_{\mathrm{O}_{2}}$ and $\sigma_{\mathrm{s}-} d c$ is the $\mathrm{SE}$ of the mean dive cycle. To compare estimates of mean $V_{\mathrm{O}_{2}}$ a form of the proximate normal test for comparing the differences between 2 estimates was used (Green et al. 2001).

\section{RESULTS}

A total of 56438 dives were included for analysis. Of the behavioural variables tested (see Table 2), dive duration and maximum dive depth, both definitions of the surface period (post-dive surface duration until the next dive, and the duration of the post dive period 
Table 2. Aptenodytes patagonicus. Results of single linear regressions between various diving variables of foraging dives and time as month of the year (from December through to April, inclusive). Individual bird was included as a random factor. All significant relationships were positive except when the dependent variable was the degree of raggedness. Intercept indicates estimated mean values in December and gradient indicates the rate of change of the diving variable with time (per month). $\mathrm{fH}_{\mathrm{dc}}$ : mean heart rate over the dive cycle; $\Sigma \mathrm{H}_{\mathrm{dc}}$ : total heart beats over the dive cycle; $d_{\text {sur: }}$ surface duration until the next dive, $d_{\text {for }}$ d duration of the post dive period between foraging dives

\begin{tabular}{|c|c|c|c|c|}
\hline \multirow[t]{2}{*}{ Diving (dependent) variable } & \multicolumn{2}{|c|}{ Parameter estimates } & \multirow{2}{*}{$\begin{array}{l}\text { Month (independent } \\
\text { variable) p-value }\end{array}$} & \multirow[t]{2}{*}{$\mathrm{r}^{2}$} \\
\hline & Intercept & Gradient & & \\
\hline Dive duration (s) & $232.1 \pm 8.5$ & $19.0 \pm 3.4$ & $<0.001$ & 0.58 \\
\hline Maximum dive depth (m) & $112.8 \pm 5.9$ & $12.5 \pm 2.4$ & $<0.001$ & 0.56 \\
\hline$d_{\text {sur }}(\mathrm{s})$ & $55.7 \pm 6.6$ & $6.9 \pm 2.5$ & $<0.05$ & 0.56 \\
\hline$d_{\text {for }}(\mathrm{s})$ & $132.6 \pm 13.1$ & $15.4 \pm 5.3$ & $<0.01$ & 0.22 \\
\hline Bottom duration (s) & $60.0 \pm 3.6$ & $3.4 \pm 1.4$ & $<0.05$ & 0.56 \\
\hline Number of wiggles per dive & $4.4 \pm 0.3$ & $0.2 \pm 0.1$ & 0.073 & 0.60 \\
\hline Wiggle rate during the bottom period (wiggles $\mathrm{min}^{-1}$ ) & $4.41 \pm 0.11$ & $-0.06 \pm 0.03$ & 0.094 & 0.72 \\
\hline Degree of raggedness $\left(\mathrm{m} \mathrm{s}^{-1}\right)$ & $0.41 \pm 0.01$ & $-0.02 \pm 0.00$ & $<0.01$ & 0.55 \\
\hline Bottom duration:dive duration & $0.26 \pm 0.01$ & $-0.01 \pm 0.00$ & 0.066 & 0.35 \\
\hline Bottom duration:dive cycle duration incorporating $d_{\text {sur }}$ & $0.26 \pm 0.01$ & $-0.01 \pm 0.00$ & 0.069 & 0.35 \\
\hline Bottom duration:dive cycle duration incorporating $d_{\text {for }}$ & $0.17 \pm 0.01$ & $-0.01 \pm 0.00$ & 0.098 & 0.48 \\
\hline Mean $\mathrm{fH}_{\mathrm{dc}}$ incorporating $d_{\text {sur }}$ (beats $\mathrm{min}^{-1}$ ) & $127.4 \pm 7.0$ & $-0.9 \pm 1.6$ & 0.570 & 0.92 \\
\hline Mean $\mathrm{fH}_{\mathrm{dc}}$ incorporating $d_{\text {for }}$ (beats $\mathrm{min}^{-1}$ ) & $131.2 \pm 7.0$ & $-1.6 \pm 1.6$ & 0.314 & 0.92 \\
\hline$\Sigma \mathrm{H}_{\mathrm{dc}}$ incorporating $d_{\mathrm{sur}}$ & $602.8 \pm 49.8$ & $66.1 \pm 15.9$ & $<0.001$ & 0.85 \\
\hline$\Sigma \mathrm{H}_{\mathrm{dc}}$ incorporating $d_{\text {for }}$ & $779.7 \pm 67.9$ & $88.5 \pm 24.1$ & $<0.01$ & 0.79 \\
\hline $\begin{array}{l}\text { Heart beats over the dive cycle per wiggle incorporating } d_{\text {sur }} \\
\left(\text { total beats wiggle }{ }^{-1} \text { ) }\right.\end{array}$ & $145.7 \pm 15.4$ & $4.6 \pm 4.7$ & 0.331 & 0.83 \\
\hline $\begin{array}{l}\text { Heart beats over the dive cycle per wiggle incorporating } d_{\text {for }} \\
\left(\text { total beats wiggle }{ }^{-1} \text { ) }\right.\end{array}$ & $188.4 \pm 22.4$ & $8.4 \pm 7.7$ & 0.282 & 0.75 \\
\hline
\end{tabular}

between foraging dives) and bottom duration all significantly increased over time throughout the summer and into the autumn, while the degree of raggedness significantly decreased over time (Fig. 2a-e). The number of wiggles per dive tended to increase over time while there was a tendency for the number of wiggles per minute of the bottom phase to decrease. There was also a tendency for the ratio of both bottom duration versus dive duration and bottom duration versus dive cycle duration to decrease over time, i.e. the proportion of foraging dive time spent in the bottom phase of dives tended to decrease through the summer/autumn.

The results of the multiple linear regressions undertaken in the present analysis are shown in Table 3. The interpretation of these results can be summarised as follows:

(1) Time into the summer/autumn was a significant, positive predictor of dive duration after either maximum dive depth or bottom duration were controlled for, but not when both these variables were controlled for simultaneously. Thus, increases in maximum dive depth and bottom duration over time contributed to the increase in dive duration.

(2) Time into the summer/autumn did not predict the number of wiggles per dive when bottom duration was controlled for. Although wiggle rate during the bottom phase decreased over time through the summer and into the autumn, there was a tendency for the number of wiggles per dive to increase over time due to bottom duration increasing.

(3) Controlling for dive duration had a larger effect on the relationship between time into the summer/ autumn and the surface duration until the next dive than did controlling for maximum dive depth. Dive duration, therefore, had more influence than did maximum dive depth on this definition of the post-dive period. The relationship between the duration of the post-dive period between foraging dives and time into the breeding season was absent when we controlled for either dive duration or maximum dive depth; thus, both these diving variables had a strong, positive influence on this definition of the post-dive period.

There was no significant relationship between mean $\mathrm{fH}_{\mathrm{dc}}$ and time into the breeding season (Table 2). However, there were significant, positive relationships between $\Sigma \mathrm{H}_{\mathrm{dc}}$ and time into the summer/autumn (Table 2), which must, therefore, be due to increases in the duration of the dive cycle. However, while differences in $\mathrm{fH}_{\mathrm{dc}}$ or $\Sigma \mathrm{H}_{\mathrm{dc}}$ can suggest differences in energy expenditure (Froget et al. 2001, Halsey et al. 2007c), differences between estimates of $\dot{V}_{\mathrm{O}_{2}}$ or estimates of $V_{\mathrm{O}_{2}}$ offer more compelling evidence in this regard (Halsey et al. 2007c). Given the significant trend in $\Sigma \mathrm{H}_{\mathrm{dc}}$ mean values of the 2 measures of $\Sigma \mathrm{H}_{\mathrm{dc}}$ across birds for each month from December to April, inclusive, were converted to estimates of mean total oxygen consumed during the dive cycle (Table 4). There were 

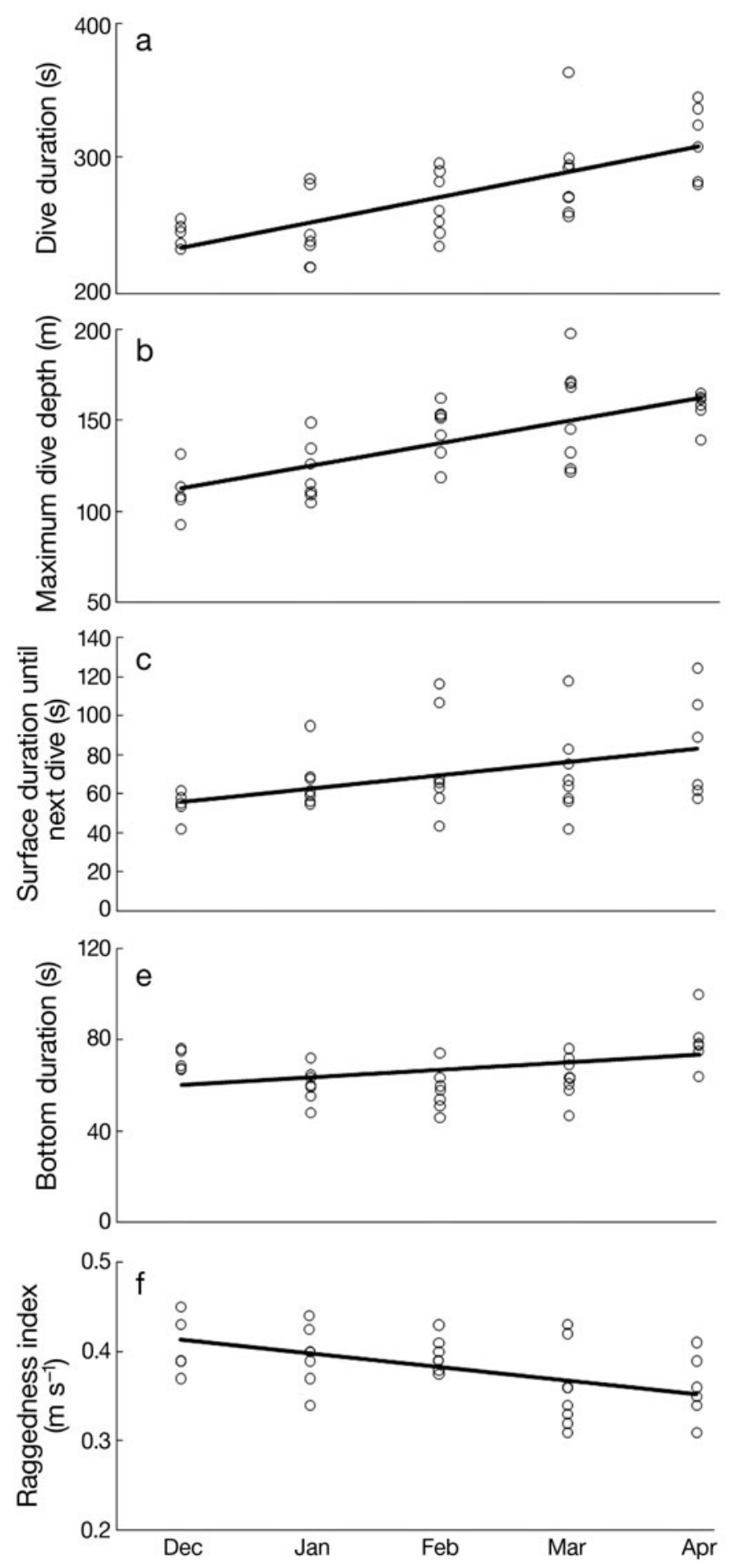

Fig. 2. Aptenodytes patagonicus. Single linear regressions of diving variables against time (as month of the year from December through to April) for 12 king penguins: (a) foraging dive duration, (b) maximum foraging dive depth, (c) surface duration, (d) bottom duration, (e) degree of raggedness. The regressions include individual bird as a random factor to account for variation between birds, which can have a considerable effect on the fit of the line to the data relative to the data points significant differences in estimates of mean $V_{\mathrm{O}_{2}}$ between December and all the later months (Table 4). These significant differences, despite the relatively large SEs of the estimates, support the interpretation of a significant positive trend in $\Sigma \mathrm{H}_{\mathrm{dc}}$ through the summer (see also Halsey et al. 2007c); i.e. the total energy costs of a foraging dive increase throughout the breeding season. However, there was no significant relationship between heart beats over the dive cycle per wiggle and time into the summer/autumn, suggesting that energy expenditure per prey capture did not change (Table 2).

\section{DISCUSSION}

King penguins foraging during April (mid-autumn) dived deeper, had longer bottom times and longer total foraging dive durations, caught more prey per foraging dive (indicated by wiggles) and required longer recovery periods after foraging dives than they did when foraging in December (at the start of summer, Fig. 3). A major influence on these changes in diving behaviour could be that myctophid fish, which are found in the vicinity of the polar front and are a primary prey of

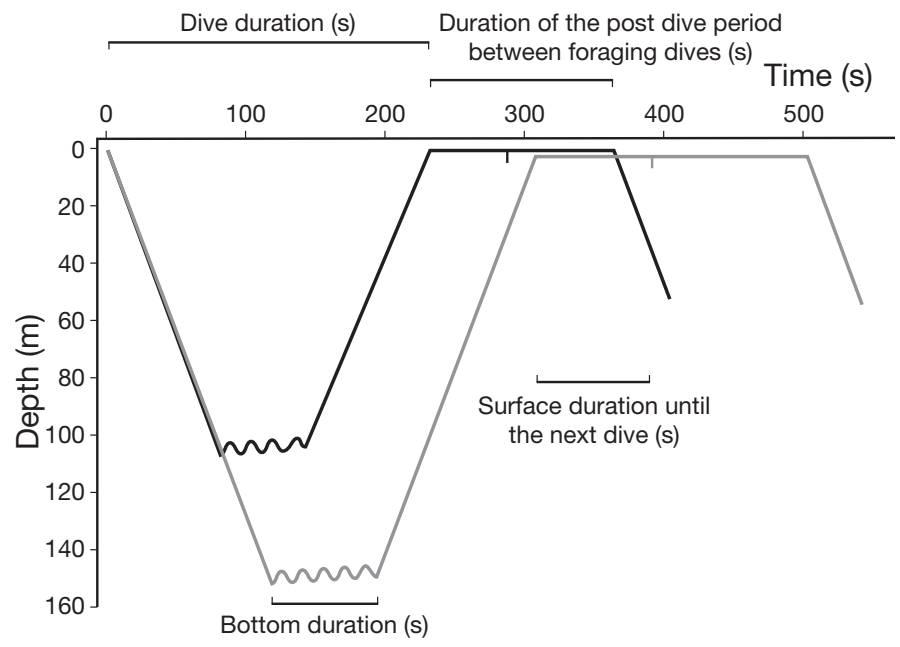

Fig. 3. Aptenodytes patagonicus. Schematic of typical foraging dives by king penguins in December (black dive profile) and April (grey dive profile) according to the means for those months of the following diving parameters: dive duration, maximum dive depth, surface duration until the next dive $\left(d_{\text {sur }}\right)$, duration of the post dive period between foraging dives $\left(d_{\text {for }}\right)$, bottom duration, number of wiggles, descent duration and ascent duration. The last 2 variables are not included in the statistical analyses of the present study. The start of the subsequent deep dive, i.e. after the duration of the post-dive period between foraging dives, is shown, while the end of the surface duration until the next dive is marked by a short vertical bar. The surface period for the April dive profile has a small vertical offset for clarity. Note that depth during the bottom phase, on average, slightly decreases from start to finish 
Table 3. Aptenodytes patagonicus. Results of multiple linear regressions of various diving variables versus time as month of the year (from December through to April, inclusive) and controlling for other diving variables. Individual bird was included as a random factor. $d_{\text {sur: }}$ surface duration until the next dive; $d_{\text {for }}$ d duration of the post dive period between foraging dives

\begin{tabular}{|c|c|c|c|c|c|c|c|}
\hline \multirow{2}{*}{$\begin{array}{l}\text { Diving (dependent) } \\
\text { variable }\end{array}$} & \multirow{2}{*}{$\begin{array}{l}\text { Month } \\
\text { p-value }\end{array}$} & \multirow{2}{*}{$\begin{array}{l}\text { Diving (independent) } \\
\text { variable(s) }\end{array}$} & \multicolumn{3}{|c|}{ Parameter estimates } & \multirow{2}{*}{$\begin{array}{c}\text { Diving } \\
\text { (independent) } \\
\text { variable } \\
\text { p-value }\end{array}$} & \multirow{2}{*}{$r^{2}$} \\
\hline & & & Intercept & $\begin{array}{c}\text { Month } \\
\text { (independent) } \\
\text { variable }\end{array}$ & $\begin{array}{c}\text { Diving } \\
\text { (independent) } \\
\text { variable(s) }\end{array}$ & & \\
\hline \multirow[t]{4}{*}{ Dive duration (s) } & $<0.05$ & Maximum dive depth & $120.0 \pm 24.4$ & $7.6 \pm 3.6$ & $1.0 \pm 0.2$ & $<0.001$ & 0.82 \\
\hline & $<0.001$ & Bottom duration & $157.4 \pm 25.3$ & $15.9 \pm 3.1$ & $1.2 \pm 0.4$ & $<0.01$ & 0.61 \\
\hline & 0.228 & Maximum dive depth & $37.7 \pm 25.8$ & $3.6 \pm 2.9$ & $1.1 \pm 0.2$ & $<0.001$ & 0.91 \\
\hline & & Bottom duration & & & $1.2 \pm 0.3$ & $<0.001$ & \\
\hline \multirow{3}{*}{$\begin{array}{l}\text { Number of wiggles per dive } \\
d_{\text {sur }}(\mathrm{s})\end{array}$} & 0.205 & Bottom duration & $0.3 \pm 0.4$ & $-0.1 \pm 0.0$ & $0.1 \pm 0.0$ & $<0.001$ & 0.95 \\
\hline & 0.424 & Dive duration & $9.7 \pm 30.7$ & $2.9 \pm 3.6$ & $0.2 \pm 0.1$ & 0.140 & 0.62 \\
\hline & 0.064 & Maximum dive depth & $54.9 \pm 23.8$ & $6.8 \pm 3.5$ & $0.0 \pm 0.2$ & 0.971 & 0.56 \\
\hline \multirow[t]{2}{*}{$d_{\text {for }}(\mathrm{s})$} & 0.614 & Dive duration & $-12.7 \pm 65.2$ & $3.7 \pm 7.2$ & $0.6 \pm 0.3$ & $<0.05$ & 0.46 \\
\hline & 0.404 & Maximum dive depth & $43.8 \pm 48.6$ & $6.1 \pm 7.2$ & $0.8 \pm 0.4$ & 0.070 & 0.48 \\
\hline
\end{tabular}

Table 4. Aptenodytes patagonicus. Mean total heart beats over the dive cycle $\left(\Sigma \mathrm{H}_{\mathrm{dc}}\right) \pm \mathrm{SE}$ (where $\Sigma \mathrm{H}_{\mathrm{dc}}$ incorporates the surface duration until the next dive, $d_{\text {sur }}$ and where it incorporates the duration of the post-dive period between foraging dives, $d_{\text {for }}$ ) and the estimates of total oxygen consumption over the dive cycle $\left( \pm \mathrm{SE}_{\mathrm{E}}\right)$ associated with these heart beat measurements. In the 2 right-hand columns, values not accompanied by letters in common are significantly different from the others within the same column, $\mathrm{p}<0.05$. The values of $\Sigma \mathrm{H}_{\mathrm{dc}}$ were analysed by testing for significant trends (see text for details)

\begin{tabular}{|lcccc|}
\hline Month & $\begin{array}{c}\Sigma \mathrm{H}_{\mathrm{dc}} \\
\text { incorporating } \\
d_{\text {sur }}\end{array}$ & $\begin{array}{c}\Sigma \mathrm{H}_{\mathrm{dc}} \\
\text { incorporating } \\
d_{\text {for }}\end{array}$ & $\begin{array}{c}\text { Estimates of mean total oxygen } \\
\text { consumed over the dive cycle } \\
\text { incorporating } d_{\text {sur }}(\mathrm{ml})\end{array}$ & $\begin{array}{c}\text { Estimates of mean total oxygen } \\
\text { consumed over the dive cycle } \\
\text { incorporating } d_{\text {for }}(\mathrm{ml})\end{array}$ \\
\hline December & $570.7 \pm 16.1$ & $701.4 \pm 9.9$ & $937.9 \pm 80.3 \mathrm{a}$ & $1153.0 \pm 98.2 \mathrm{a}$ \\
January & $698.8 \pm 53.2$ & $904.1 \pm 47.7$ & $1192.0 \pm 103.0 \mathrm{~b}$ & $1562.6 \pm 146.4 \mathrm{~b}$ \\
February & $768.4 \pm 70.4$ & $1064.0 \pm 90.9$ & $1308.6 \pm 121.6 \mathrm{~b}$ & $1829.8 \pm 166.4 \mathrm{~b}$ \\
March & $768.4 \pm 66.2$ & $1010.5 \pm 48.4$ & $1300.8 \pm 118.6 \mathrm{~b}$ & $1772.9 \pm 154.3 \mathrm{~b}$ \\
April & $884.7 \pm 125.5$ & $1140.1 \pm 187.7$ & $1435.8 \pm 138.1 \mathrm{~b}$ & $1826.7 \pm 203.0 \mathrm{~b}$ \\
\hline
\end{tabular}

king penguins living in the Southern Indian Ocean, descend to greater depths as months progress from summer through to winter (Lancraft et al. 1991, Kozlov et al. 1993). Despite this, while there was an increase in the total energetic cost of each foraging dive per se (mean total oxygen consumed over the dive cycle) over time, there was no change in the rate of energy expenditure (mean heart rate over the dive cycle) nor in the energetic cost of each prey capture (heart beats per wiggle).

\section{Behavioural changes over time}

As the months progressed through summer into autumn, both the duration of foraging dives by king penguins and the depths of their foraging dives increased. All birds in the present study were incubating eggs at the time that data recording began and all were brooding later on in the summer. These findings are therefore in agreement with those of Charrassin et al. (1998) and Charrassin et al. (2002), who recorded greater foraging dive durations and depths by king penguins once they reached the brooding stage of the breeding cycle, and Moore et al. (1999) who found that maximum dive depth increased between February and August.

In the present study there was also an increase in bottom duration of each dive, which although in part explains the increase in total dive duration, represented a reduced proportion of the dive and of the dive cycle over time. Thus, foraging dives into the autumn are not simply 'scaled-up' versions of those undertaken earlier in the summer (Fig. 3). Rather, king penguins exhibit an adjusted proportional time budget during foraging dives in different parts of the incubating and chick-rearing seasons. It is during the bottom phase that the majority of wiggles by king penguins occur, which provide a proxy of prey capture events (Bost et al. 2007). While there was a tendency for the wiggle rate during the bottom phase of a foraging dive to decrease over the season, due to the increase in bottom duration there was a tendency for the number of wiggles in a foraging dive to increase, i.e. the number 
of prey caught per dive probably increased over the season.

As prey are likely to be more available to king penguins during the bottom phase of the bird's dive than in other parts of the dive, the penguins in the present study were spending a smaller proportion of their dive time in areas of prey abundance in the autumn compared with the summer. This may indicate that into the autumn the king penguins were reaching the limits of their breath-holding capacity (Carbone \& Houston 1994), e.g. the greater the depth to which they dived the more limited was their bottom duration. However, this finding is in contrast to that of Charrassin et al. (2002) who found a small increase in the proportion of the dive cycle spent in the bottom phase from summer into autumn. Perhaps this represents a difference in the type and/or distribution of prey available between the years studied in Charrassin et al. (2002) and in the present paper.

Pochards Aythya ferina consume less food during the bottom phase of a dive when food is less available (Carbone \& Houston 1994). Similarly, a reduction in prey density, or in detectability of that prey, as the breeding season progresses may explain the tendency for wiggle rate in king penguins during the bottom phase of foraging dives to decrease over time. If this is the case, it is probable that by increasing maximum foraging dive depths through the summer and autumn, king penguins are attempting to compensate for a gradual increase in the depth that myctophid fish inhabit by tracking the seasonal movement of the fish, to some degree, to limit the decrease in density of, or ease of detecting, prey in visited patches. This would mean that the plasticity observed in diving depth is directly attributable to changes in prey location and availability. In turn, the increase in bottom duration, which results in more prey captures per foraging dive at this time of year than earlier in the breeding season, can be interpreted as a direct response to the increasing energy demands of the chick. This assumes that prey size and energy content are constant over time. These increased bottom durations, and hence prey captures per foraging dive, raise the question as to why king penguins do not always undertake such dives with a long duration at the bottom. It is known that animals will not necessarily work optimally during periods of foraging under all conditions (Halsey et al. 2006b), perhaps because there is simply not a requirement to do so. Charrassin et al. (2002) suggested that in the summer, availability of food may be sufficient so that king penguins can afford to spend a shorter amount of time at the bottom than they do later in the season. If this is the case it is unclear why surface periods between foraging dives are short during the summer, which suggests that time is a constraint. How- ever, foraging dives with relatively short bottom durations may still be optimal under particular foraging circumstances. For example, Houston \& Carbone (1992) developed a qualitative optimal foraging model for airbreathing divers that predicted bottom duration could increase with foraging depth up to a point when time during the bottom phase was being maximised. This was supported by laboratory data for foraging pochards (Carbone \& Houston 1994) as well as the data from the present study.

The significant decrease in the degree of raggedness of foraging dives over time through the breeding season (close to $25 \%$ reduction between December and April) indicates that the range of depths of the bird in the water column while capturing prey decreased (Fig. 2e). Such changes in diving behaviour may be indicative of changes in the vertical distribution of prey within patches. This trend contrasts with gentoo penguins Pygoscelis papua, which increase the raggedness of their dives over time as the austral summer/ autumn progresses. The change in raggedness of dives in gentoo penguins is probably due to a change in diet from benthic fish to crustaceans, which results in a switch from 2 dimensional benthic foraging to 3 dimensional pelagic foraging (Lescroël \& Bost 2005). There are a number of possible explanations for the reduction in raggedness of king penguin foraging dives over time. For example, the anti-predator responses of the prey may affect the raggedness of foraging dives; perhaps earlier in the year the species of myctophid fish upon which king penguins prey (Cherel \& Ridoux 1992) scatter more rapidly upon detection. Indeed, greater scattering may also explain shorter bottom durations in the summer; king penguins may prefer to return to the surface in such cases and prepare for a new dive while allowing the prey to reform into a denser patch.

\section{Changes in diving energetics over time}

In king penguins, in contrast to most other penguins, the period of highest energy demand on them (during chick rearing) is not restricted to the summer when food availability is at its highest. The total energetic demand on king penguins is likely to increase through the summer months and then continue to increase into the autumn (Charrassin et al. 1999). The present study provides evidence to confirm that due to the increased duration of foraging dive cycles over time, which results from both the increases in dive duration and in surface duration, the total energy cost of a foraging dive cycle for king penguins was higher in later months.

However, there was no increase in the rate of energy expenditure during foraging dives. It is now known 
how changes in diving behaviour during deep dives affect the energy costs of those dives in king penguins during the summer. Halsey et al. (2007c) found that the rate of energy expenditure over the dive cycle increased when maximum dive depth and post-dive surface duration increased, and when foraging dive duration and bottom duration decreased. In the present study, as the summer progressed and autumn ensued, these 4 diving variables all increased (Fig. 2a-d). Therefore, they appear to have cancelled themselves out, resulting in a more or less consistent rate of energy expenditure during foraging dives through the summer and autumn. This finding is somewhat in contrast to the seasonal energetics of macaroni penguins, which show a reduced rate of oxygen consumption during diving behaviour in winter compared with that in summer (Green et al. 2005a). Green et al. (2005a) suggest that changes in the distribution of fat stores and the presence of post-moult feathers may affect thermal conductance sufficiently to explain their observations.

Furthermore, due to the increase in the number of wiggles as foraging dive duration increased over time, the energy costs of diving per prey item captured did not change as the season progressed. Thus, despite the fact that myctophid fish inhabit deeper waters later in the summer and into the autumn, king penguins do not invest more energy per unit prey captured. This may be crucial to the breeding success of king penguins as they increase the number of prey captures through the breeding season in response to the increasing quantity of food required by the growing chick.

\section{The recovery element of foraging dives}

The increase in surface duration through the summer/autumn is most strongly associated with the increase in duration of foraging dives. This is consistent with the positive relationships between surface duration and dive duration found in many other species of penguin (e.g. Tremblay \& Cherel 2003). Presumably this reflects the increased recovery time required after the longer, and hence generally more energetic, dives that are undertaken as the breeding season progresses throughout the summer and autumn. In turn, the relatively small effect of maximum depth of foraging dives on changes in $d_{\text {sur }}$ to any depth over time suggests that the depth of foraging dives per se does not have a large effect on the energetic costs of the dive for king penguins, at least the aerobically metabolised component, which supports the findings of Halsey et al. (2007c).

However, in terms of the duration of the period between one foraging dive and the next $\left(d_{\text {for }}\right)$, not only the increase in dive duration, but also the increase in maximum depth over time, is strongly associated with the increase in surface duration. If at least some of the shallow dives between foraging dives aid in lactate metabolism then we might expect the duration of time spent in these shallow dive cycles to increase after longer foraging dives, as is shown by the increase in the duration of $d_{\text {for }}$ through the breeding season. Therefore, this may offer support for a significant degree of anaerobic metabolism by king penguins during relatively long dives, as has been suggested by Kooyman et al. (1992). Also, such an anaerobic component to long foraging dives may increase through the summer and into the autumn as the duration of dives increases. However, the increase in duration of the postdive period between foraging dives as a function of the depth of foraging dives as well as of their duration (as also reported by Charrassin et al. 2002) may indicate that the function of some of the subsequent shallow dives is, at least in part, to stop the onset of decompression sickness caused by super-saturation of nitrogen gas in the blood and tissues (Kooyman 1989). This is because deeper dives allow a greater absorption of nitrogen gas into the blood from the respiratory system (Kooyman \& Ponganis 1998). Fahlman et al. (2007) have suggested that the relatively shallow dives, which can still be several tens of metres deep, may be undertaken after a deep foraging dive, or series of deep dives, to help remove nitrogen that has built up in the adipose tissues. Thus, as the summer progresses into autumn and foraging dives by king penguins become deeper, the greater time spent between such dives, which includes more frequent shallow diving, may be to avoid decompression sickness.

\section{CONCLUSIONS}

The changes in the dive-time budgeting of king penguins foraging over the summer and autumn months, coupled with the tendency for the number of wiggles per foraging dive to increase, are evidence for an ability of king penguins to adjust their behaviours to increase the number of prey captures per dive. King penguins are able to keep the cost of prey capture constant despite these differences. Such plasticity may be fundamental for king penguins to be able to rear a chick through the summer and autumn, in the face of changes in both prey availability (Charrassin et al. 2002) and the energetic demands of the chick, such that the chick is able to withstand the winter fasting period (Weimerskirch et al. 1992).

Acknowledgements. This project would not have been possible without the support of the people of the 40th, 41st and 42nd missions in Crozet. We also thank P. Cassey for his assis- 
tance in deriving the second equation presented in this paper. J. A. Green provided important comments on a draft version of this paper. This study was funded by a grant from the Natural Environment Research Council (NERC), UK, (NER/A/S/2000 001074) with financial support also provided by Institut Paul Emile Victor (IPEV). Ethical approval for all procedures was granted by the ethics committee of the French Polar Research Institute (IPEV) and of the Ministère de l'Environnement. We also followed the provisions of the UK Animal (Scientific Procedures) Act 1986, especially those set out by the Home Office in the Official Guidance on the operation of the Act.

\section{LITERATURE CITED}

Bevan RM, Keijer E, Butler PJ (1992) A method for controlling the feeding behaviour of aquatic birds: heart rate and oxygen consumption during dives of different duration. J Exp Biol 162:91-106

Bost CA, Handrich Y, Butler PJ, Fahlman A, Halsey LG, Woakes AJ, Ropert-Coudert Y (2007) Change in dive profiles as an indicator of feeding success in king and Adélie penguins. Deep-Sea Res II 54:248-255

Butler PJ (2004) Metabolic regulation in diving birds and mammals. Respir Physiol Neurobiol 141:297-315

Carbone C, Houston AI (1994) Patterns in the diving behaviour of the pochard, Aythya ferina: a test of an optimality model. Anim Behav 48:457-465

Charrassin JB, Bost CA (2001) Utilisation of the oceanic habitat by king penguins over the annual cycle. Mar Ecol Prog Ser 221:285-297

> Charrassin JB, Bost CA, Pütz K, Lage J, Dahier T, Zorn T, Le Maho Y (1998) Foraging strategies of incubating and brooding king penguins Aptenodytes patagonicus. Oecologia 114:194-201

Charrassin JB, Bost CA, Pütz K, Lage J, Dahier T, Le Maho Y (1999) Changes in depth utilization in relation to the breeding stage: a case study with the king penguin (Aptenodytes patagonicus). Mar Ornithol 27:43-47

Charrassin JB, Le Maho Y, Bost CA (2002) Seasonal changes in the diving parameters of king penguins (Aptenodytes patagonicus). Mar Biol 141:581-589

Cherel Y, Ridoux V (1992) Prey species and nutritive value of food fed during summer to king penguin Aptenodytes patagonica chicks at Possession Island, Crozet Archipelago. Ibis 134:118-127

Cherel Y, Ridoux V, Rodhouse PG (1996) Fish and squid in the diet of king penguin chicks, Aptenodytes patagonicus, during winter at sub-antarctic Crozet Islands. Mar Biol 126:559-570

Dallal G, Wilkinson L (1986) An analytical approximation to the distribution of Lillefor's test statistic for normality. Am Stat 40(4):294-296

Fahlman A, Handrich Y, Woakes AJ, Bost CA, Holder R, Duchamp C, Butler PJ (2004) Effect of fasting on the $\dot{V}_{\mathrm{O}_{2}}-f_{\mathrm{h}}$ relationship in king penguins, Aptenodytes patagonicus. Am J Physiol-Reg I 287:R870-R877

Fahlman A, Schmidt A, Handrich Y, Woakes AJ, Butler PJ (2005) Metabolism and thermoregulation during fasting in king penguins, Aptenodytes patagonicus, in air and water. Am J Physiol 289:R670-R679

Fahlman A, Schmidt A, Jones D, Bolstrom B, Handrich Y (2007) To what extent might $\mathrm{N}_{2}$ limit dive performance in king penguins? J Exp Biol 210:3344-3355

Froget G, Butler PJ, Handrich Y, Woakes AJ (2001) Heart rate as an indicator of oxygen consumption: influence of body condition in the king penguin. J Exp Biol 204:2133-2144
Froget G, Butler PJ, Woakes AJ, Fahlman A, Kuntz G, Le Maho Y, Handrich Y (2004) Heart rate and energetics of free-ranging king penguins (Aptenodytes patagonicus). J Exp Biol 207:3917-3926

Gauthier-Clerc M, Le Maho Y, Clerquin Y, Drault S, Handrich $Y$ (2000) Penguin fathers preserve food for their chicks. Nature 408:928-929

Goodman L (1960) On the exact variance of products. J Am Stat Assoc 55:708-713

Green JA, Butler PJ, Woakes AJ, Boyd IL, Holder RL (2001) Heart rate and rate of oxygen consumption of exercising macaroni penguins. J Exp Biol 204:673-684

> Green JA, Boyd IL, Woakes AJ, Green CJ, Butler PJ (2005a) Do seasonal changes in metabolic rate facilitate changes in diving behaviour? J Exp Biol 208:2581-2593

Green JA, Boyd IL, Woakes AJ, Warren NL, Butler PJ (2005b) Behavioural flexibility during year-round foraging in macaroni penguins. Mar Ecol Prog Ser 296:183-196

- Green J, Boyd IL, Woakes AJ, Warren NL, Butler P (2009) Evaluating the prudence of parents: daily energy expenditure throughout the annual cycle of a free-ranging bird, the macaroni penguin Eudyptes chrysolophus. J Avian Biol 40:529-538

Halsey LG, Woakes AJ, Butler PJ (2003) Testing optimal foraging models for air-breathing divers. Anim Behav 65: 641-653

Halsey LG, Blackburn TM, Butler PJ (2006a) A comparative analysis of the diving behaviour of birds and mammals. Funct Ecol 20:889-899

Halsey LG, Brand OJ, Woakes AJ, Butler PJ (2006b) Experiments on single diving animals in the laboratory often measure dives of decreased effort. Ibis 148:164-166

Halsey LG, Bost CA, Handrich Y (2007a) A thorough and quantified method for classifying seabird diving behaviour. Polar Biol 30:991-1004

Halsey LG, Fahlman A, Handrich Y, Schmidt A, Woakes AJ, Butler PJ (2007b) How accurately can we estimate energetic costs in a marine top predator, the king penguin? Zoology 110:81-92

Halsey LG, Handrich Y, Fahlman A, Schmidt A and others $(2007 \mathrm{c})$ Fine-scale analyses of diving energetics in king penguins Aptenodytes patagonicus: how behaviour affects costs of a foraging dive. Mar Ecol Prog Ser 344: 299-309

> Halsey LG, Butler PJ, Fahlman A, Bost CA, Woakes AJ, Handrich Y (2008) Modeling the marine resources consumed in raising a king penguin chick: an energetics approach. Physiol Biochem Zool 81:856-867

Houston AI, Carbone C (1992) The optimal allocation of time during the diving cycle. Behav Ecol 3:255-265

Hull CL (2000) Comparative diving behaviour and segregation of the marine habitat by breeding Royal Penguins, Eudyptes schlegeli, and eastern Rockhopper Penguins, Eudyptes chrysocome filholi, at Macquarie Island. Can J Zool 78:333-345

Kato A, Watanuki Y, Naito Y (2003) Annual and seasonal changes in foraging site and diving behaviour in Adelie penguins. Polar Biol 26:389-395

Kooyman GL (1989) Diverse divers, physiology and behaviour. Springer-Verlag, Berlin

> Kooyman GL, Ponganis PJ (1998) The physiological basis of diving to depth: birds and mammals. Annu Rev Physiol 60: 19-33

> Kooyman GL, Cherel Y, Le Maho Y, Croxall JP, Thorson PH, Ridoux V, Kooyman CA (1992) Diving behaviour and energetics during foraging cycles in King penguins. Ecol Monogr 62:143-161 
Kozlov AN, Shust KV, Zemsky AV (1993) Seasonal and interannual variability in the distribution of Electrona carlsbergi in the southern polar front area (the area to the north of South Georgia is used as an example). In: Selected Scientific Papers, Scientific Committee for the Conservation of Antarctic Living Resources (CCAMLR), 1990, Hobart, p 320-337

Lancraft TM, Hopkins TL, Torres JJ, Donnelly J (1991) Oceanic micronektonic/macrozooplanktonic community structure and feeding in ice covered Antarctic waters during the winter (AMERIEZ 1988). Polar Biol 11:157-167

Le Maho Y, Gendner JP, Challet E, Bost CA and others (1993) Undisturbed breeding penguins as indicators of changes in marine resources. Mar Ecol Prog Ser 95:1-6

Lescroël A, Bost CA (2005) Foraging under constrasting oceanographic conditions: the gentoo penguin at Kerguelen Archipelago. Mar Ecol Prog Ser 302:245-261

Moore GJ, Wienecke B, Robertson G (1999) Seasonal change in foraging areas and dive depths of breeding king penguins at Heard Island. Polar Biol 21:376-384

Pütz K, Bost CA (1994) Feeding behavior of free-ranging king penguins (Aptenodytes patagonicus). Ecology 75:489-497

Rodary D, Wienecke BC, Bost CA (2000) Diving behaviour of Adélie penguin (Pygoscelis adeliae) at Dumont D'Urville, Antarctica: nocturnal patterns of diving and rapid adaptations to changes in sea-ice condition. Polar Biol 23: $113-120$

Ropert-Coudert Y, Bost CA, Handrich Y, Bevan RM, Butler PJ, Woakes AJ, Le Maho Y (2000) Impact of externally

Editorial responsibility: Rory Wilson, Swansea, UK attached loggers on the diving behaviour of the king penguin. Physiol Biochem Zool 73:438-445

Slater PJB, Lester NP (1982) Minimising errors in splitting behaviour into bouts. Behaviour 79:153-161

Stonehouse B (1960) The king penguin Aptenodytes patagonica of South Georgia. I. Breeding behaviour and development. Falkland Islands Dependencies Survey Scientific Report No. 23, Colonial Office, London

Tremblay Y, Cherel Y (2003) Geographic variation in the foraging behaviour, diet and chick growth of rockhopper penguins. Mar Ecol Prog Ser 251:279-297

van Heezik YM, Seddon PJ, Du Plessis C, Adams NJ (1993) Differential growth of king penguin chicks in relation to date of hatching. Colon Waterbirds 16:71-76

Walsberg GE, Hoffman TCM (2005) Direct calorimetry reveals large errors in respirometric estimates of energy expenditure. J Exp Biol 208:1035-1043

Weimerskirch H, Stahl JC, Jouventin P (1992) The breeding biology and population dynamics of King Penguins Aptenodytes patagonica on the Crozet Islands. Ibis 134:107-117

Wilson RP (1995) Foraging ecology. In: Williams TD (ed) The penguins. Oxford University Press, Oxford, p 81-106

> Woakes AJ, Butler PJ, Bevan RM (1995) Implantable data logging system for heart rate and body temperature: its application to the estimation of field metabolic rates in Antartic predators. Med Biol Eng Comput 33:145-151

Zasel'sliy V, Kudrin B, Poletayev V, Chechenin SC (1985) Some features of the biology of Electrona carlsbergi (Taning) (Mycophidae) in the Atlantic sector of the Antarctic. J Ichthyol 25:163-166

Submitted: September 17, 2009; Accepted: December 1, 2009 Proofs received from author(s): February 15, 2010 